\title{
Studied on the effect of refueling rate on fuel system refueling based on STAR-CCM+
}

\author{
Chongzhi Zhong*, Chunbei Dai, and Taiyu Zhang \\ China Automotive Technology and Research Center Co., Ltd, China
}

Keywords: fuel system, filler pipe, simulation, ORVR.

\begin{abstract}
A model of fuel system which is with ORVR is established based on STAR CCM +, to study the influence of different refueling velocity on the formation of liquid seal in refueling process. The simulation results show that the increase of refueling rate leads to the formation of liquid seal in the process of fuel flow, but it will lead to the deterioration of refueling smoothness. When the refueling rate is $15 \mathrm{~L} / \mathrm{min}$, there is no liquid seal formed at the bottom of the refueling pipe, because of the small gas resistance formed in the refueling process, and when the refueling flow rate reaches $37 \mathrm{~L} / \mathrm{min}$, a stable dynamic liquid seal can be formed at the bottom of the refueling pipe but the fuel accumulation at the refueling port has taken place. When the refueling flow rate reaches $40 \mathrm{~L} / \mathrm{min}$ and $45 \mathrm{~L} / \mathrm{min}$, a stable dynamic liquid seal is formed at the bottom of the refueling pipe at $4 \mathrm{~s}$, but until 4 seconds, fuel has been submerged in the refueling muzzle. At 10 seconds, the fuel accumulation state is the same as 5 seconds, indicating that the gun PSO had taken happened.
\end{abstract}

$\begin{array}{ll}\text { Abbreviations } \\ \text { ORVR } & \text { Onboard Refueling Vapor Recovery } \\ \text { ICV } & \text { Intake Check Valve } \\ \text { PSO } & \text { Pre-Shut Off } \\ \text { VOCs } & \text { Volatile Organic Compounds }\end{array}$

\section{Introduction}

Evaporation emission is the important source of VOCs emissions from vehicles in the world[1-2-3-4]. VOCs are important precursors of secondary organic aerosols and ozone, which is called "three effects". The emission of VOCs from vehicle is an important part of VOCs artificial source[3-4]. In recent years, with the tightening of emission standards, the total amount of vehicle exhaust emissions have decreased year by year, while evaporation emissions have gradually increased in the proportion of total vehicle VOCs emissions.

At present, China has gradually begun to implement China 6[5], in which significantly changes have taken place in the control of fuel evaporation emissions with reference to the requirements of the EPA[6-7-8]. On the one hand, the hot soak and diurnal bleed loss test is

\footnotetext{
*Corresponding author: zhongchongzhi@catarc.ac.cn
} 
required, the pretreatment process increases high temperature and high temperature pretreatment, the diurnal test time is increased from $24 \mathrm{~h}$ to $48 \mathrm{~h}$, and the limit value is from $2 \mathrm{~g} /$ test to $0.7 \mathrm{~g} /$ test (the deterioration coefficient $0.06 \mathrm{~g} /$ test should be considered). On the other hand, the refueling emission test requirements are added, in which the vechile exhaust test requirements are added in the pretreatment process, and the limit value is set to $0.05 \mathrm{~g} / \mathrm{L}$ (the deterioration coefficient $0.01 \mathrm{~g} / \mathrm{L}$ should be considered).

Before the fuel tank is refueled, there is a certain concentration of oil and gas stay in the tank. During the refueling of vehicles, as the liquid oil is continuously added through the fuel gun, the pressure in the fuel tank rises due to the liquid surface rising, and the fuel flow which is rapidly leading to the mixing severely disturbed, so that the oil and gas are discharged from the return air pipe through the fuel tank port [9-12]. The evaporative emission from cars can promote the formation of ozone and seriously harm to human health. Some researchers have conducted a large number of theoretical studies on automotive evaporative emissions. Marek C. Lockhart from Ford Motor Company proposed three mathematical models for calculating HC evaporative emissions when refueling in 1997[13].It is an ideal solution model, a model for calculating molecular weight based on pressure, and a direct empirical model respectively. Mastroianni, University of Windsor, Canada, designed a simplified transparent rectangular fuel tank to explore the effect of diameter of return air pipe and refueling test conditions on PSO (Pre-Shut Off)[14]. Dr. Christopher John Quigley of the University of Texas at Austin studied the refueling emissions, running loss emissions, hot-soak loss emissions, and diurnal breathe loss emissions related to automotive evaporative emissions, and analyzed the specifics of automotive evaporative emissions, and studied the potential of various evaporative emissions for the formation of ozone by oxidation [15].Yamada et al. studied the control of fuel vapors in the Japanese about vehicles. The study of the fuel composition shows that $\mathrm{C} 4$ olefins have a greater impact on refueling emissions. The impact of C4 olefins on refueling emissions controlled based on chemical methods can achieve similar levels compared with ORVR vehicle refueling emissions [16]. Dong Kyu Kim et al. studied the kinetics of adsorption and desorption of canisters which is matching ORVR systems, and provided a reference for matching ORVR systems by establishing dynamic models [17]. Cai Jinrong from Jiangsu University introduced the refueling emission mechanism of ORVR and conducted a pilot study. The results show that if only canisters installed could reduce refueling emissions by approximately $15.7 \%$, while installing an on-board refueling vapor recovery system on average reduced by more than $94 \%$ [18].

The requirement of refueling rate in EPA is $37.1 \mathrm{~L} / \mathrm{min}$, and the refueling rate can be as low as $15.1 \mathrm{~L} / \mathrm{min}$ under special circumstances[6-7-8]. The main reason for the refueling rate is not too low is that the smaller the refueling rate is, the more difficult it is to form a dynamic liquid seal in the refueling process. However, the refueling rate is too large, the greater is the resistance of the refueling process, the easier to form the splash. While in filling station, the initial refueling rate of the fuel gun is hard to reach $37 \mathrm{~L} / \mathrm{min}$ immediately. Therefore, it is necessary to ensure that the refueling flow rate can form a dynamic liquid seal before the flow rate is reached $37 \mathrm{~L} / \mathrm{min}$ to ensure that the hydrocarbon emissions in the refueling process meet the requirements of the regulations. Similarly, the refueling rate of filling station is generally $45 \mathrm{~L} / \mathrm{min}$, or even higher. So in order to ensure that the vehicle refueling in the market meets the requirements of regulations, the characteristics of refueling emission at high velocity are studied.Jiangsu University [19] researchment have shown that refueling rate increases may make the risk of fuel backinjection more obviously.So it is necessary to study the influence of refueling emission under different refueling rate.

3D- modeling of the fuel system is set up based on STAR CCM + to study the refueling smoothness of the filler pipe and the formation of dynamic liquid sealing under different refueling rates, which provides a reference for satisfying the design of fueling emission control. 


\section{3D-Model Set Up}

The entire fuel tank model of surface and grid are processed by Hypermesh. And then import StarCCM+ to generate a hexahedral structured grid for 3D modeling. As shown in Figure 1(a), the surface treatment of the fuel tank and the refinement of the grid. And the division of the surface grid of the fuel system. In order to shorten the calculation time, the canister does not participate in the simulation-calculation and the outlet pressure of $900 \mathrm{~Pa}$ is used instead of the ventilation resistance of the canister. Figure 1(b) shows the fuel tank system, which includes a fuel filler pipe, a canister, a fuel tank body, a GVV valve, an FLVV valve, an ICV valve, a canister solenoid valve, etc. In order to keep the same with the actual original model, the grid encryption is performed at the filler port and the place where the fuel gun contacts, and the connection between the return gas pipe and the filler port.
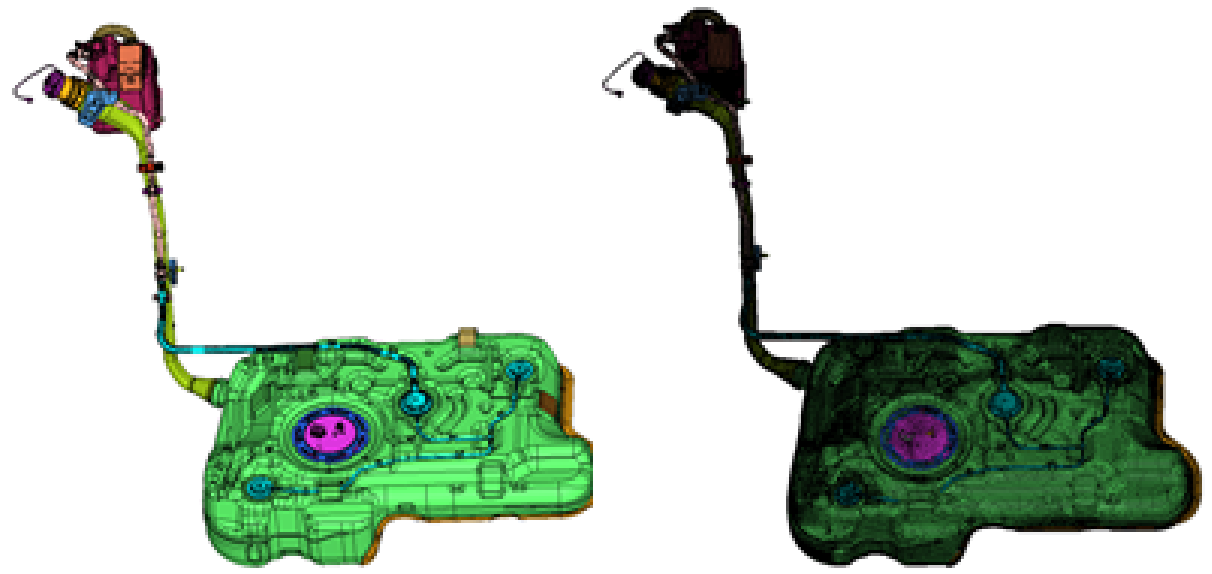

Fig. 1 (a)3D model of fuel system.

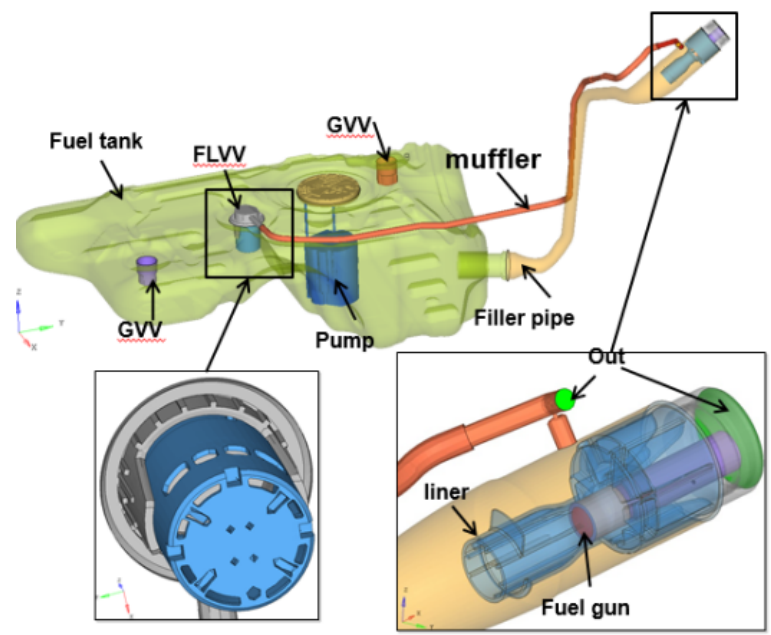

Fig. 1 (b) 3D model of fuel system.

\subsection{Boundary conditions}

Table 1 is the input of boundary parameters. Gasoline density is based on the test in laboratory. The inlet pressure input is $900 \mathrm{~Pa}$ which is reference about the adsorption 
resistance of the canister. According to the requirements in the regulations of China 6 , the fueling rate is set to $37 \mathrm{~L} / \mathrm{min}$, fuel temperature is set to $20^{\circ} \mathrm{C}$.

Table 1. Boundary parameters.

\begin{tabular}{ll}
\hline Gasoline $\rho(\mathrm{kg} / \mathrm{m} 3)$ & 740 \\
\hline Gasoline $\mu(\mathrm{Pa} \cdot \mathrm{s})$ & 0.042 \\
Air $\rho(\mathrm{kg} / \mathrm{m} 3)$ & Ideal gas \\
Air $\mu(\mathrm{Pa} \cdot \mathrm{s})$ & $1.855 \mathrm{E}-5$ \\
Inlet pressure & $0 \mathrm{~Pa}$ \\
Outlet pressure & $900 \mathrm{~Pa}$ \\
Refueling rate & $15 \mathrm{~L} / \mathrm{min}, 37$ \\
& $\mathrm{~L} / \mathrm{min}, 40 \mathrm{~L} / \mathrm{min}, 45 \mathrm{~L} / \mathrm{min}$ \\
Fuel temperature & $20^{\circ} \mathrm{C}$ \\
Tank volume & $55 \mathrm{~L}$ \\
Number of grids & 3420000 \\
\hline
\end{tabular}

During the refueling process of the fuel system, the fluid motion includes various phenomena and characteristics such as unsteady, incompressible, turbulent, tumble, mass transfer, heat transfer, etc. During the calculation, the basic control equation of the gas flow must be satisfied: mass conservation equation, equation for conservation of momentum and energy conservation equation. If the fluid contains a mixture or interaction of different components, the system also needs to satisfy the component conservation equation: .

Mass conservation equation:

$$
\frac{\partial \rho}{\partial t}+\frac{\partial(\rho u)}{\partial x}+\frac{\partial(\rho v)}{\partial y}+\frac{\partial(\rho w)}{\partial z}=0
$$

where $\rho$ is the density, $t$ is time, $u, v, w$ is the component of the velocity vector in the $\mathrm{x}, \mathrm{y}, \mathrm{z}$ direction.

Equation for conservation of momentum:

$$
\begin{aligned}
& \frac{\partial(\rho u)}{\partial t}+\operatorname{div}(\rho u u)=\operatorname{div}(\mu \operatorname{grad} u)-\frac{\partial p}{\partial x}+S_{u} \\
& \frac{\partial(\rho v)}{\partial t}+\operatorname{div}(\rho v u)=\operatorname{div}(\mu g r a d v)-\frac{\partial p}{\partial y}+S_{v} \\
& \frac{\partial(\rho w)}{\partial t}+\operatorname{div}(\rho w u)=\operatorname{div}(\mu g r a d w)-\frac{\partial p}{\partial z}+S_{w}
\end{aligned}
$$

where, $\mu$ is the dynamic viscosity, $S_{u}, S_{v}, S_{w}$ is the generalized source term of momentum conservation equation.

Energy conservation equation:

$$
\frac{\partial(\rho T)}{\partial t}+\operatorname{div}(\rho u T)=\operatorname{div}\left(\frac{k}{c_{p}} \operatorname{grad} T\right)+S_{T}
$$


where $c_{p}$ is the specific heat capacity, $T$ is the temperature, $k$ is the heat transfer coefficient of the fluid, $S_{T}$ is the heat transfer coefficient of the fluid, sometimes referred to simply as the viscous dissipative term.

Component conservation equation:

$$
\frac{\partial\left(\rho c_{s}\right)}{\partial t}+\operatorname{div}\left(\rho u c_{s}\right)=\operatorname{div}\left(D_{s} \operatorname{grad}\left(\rho c_{s}\right)\right)+S_{s}
$$

where $c_{s}$ is the volume concentration of the component " $\mathrm{s}$ ",$\rho c_{s}$ is the mass concentration of the component, $D_{s}$ is the diffusion coefficient of the component, $S_{s}$ is the mass of the component produced by the chemical reaction per unit volume per unit time within the system.

\section{Analysis of simulation results}

\subsection{Comparison of refueling at fuel port under different refueling rates}

Table 2 shows the fuel accumulation at the refueling port under different refueling rate. When the refueling rate is $15 \mathrm{~L} / \mathrm{min}$, the fuel begins to accumulate at 1 seconds. Until the 10 seconds of refueling, the fuel accumulation at the refueling port has not missed the fuel gun, indicating that the entire refueling process is smooth, and there is no problem of back swimming and PSO.

When the refueling rate is $37 \mathrm{~L} / \mathrm{min}$, the fuel begins to accumulate at 1 seconds. Until the 10 seconds of refueling, the fuel accumulation at the refueling port has not missed the fuel gun, indicating that the entire refueling process is smooth, and there is no problem of back swimming and PSO.

When the refueling rate is $40 \mathrm{~L} / \mathrm{min}$, the fuel begins to accumulate at 1 seconds. Until 3 seconds, the fuel accumulation has been close to the refueling muzzle. At Until 5 seconds, fuel has been submerged in the refueling muzzle. At 10 seconds, the fuel accumulation state is the same as 5 seconds, indicating that the gun PSO had taken happened.

When the refueling rate is $45 \mathrm{~L} / \mathrm{min}$, the fuel begins to accumulate at 1 seconds. Until 3 seconds, the fuel accumulation has been close to the refueling muzzle. Until 4 seconds, fuel has been submerged in the refueling muzzle. At 10 seconds, the fuel accumulation state is the same as 5 seconds, indicating that the gun PSO had taken happened.

From the above analysis, it can be seen that the lower the refueling flow rate, the better the refueling smoothness performance. With the increase of the refueling flow rate, the accumulation of oil in the head of the refueling port is increasing., Or even reverse injection, causing greater fuel vapor to escape from the fuel filler.

Table 2. Comparison of refueling at fuel port under different refueling rates.

\begin{tabular}{|l|c|c|c|c|}
\hline \multirow{2}{*}{$\begin{array}{l}\text { Tim } \\
\text { e(s) }\end{array}$} & \multicolumn{4}{|c|}{ Refueling rate } \\
\cline { 2 - 5 } & $15(\mathrm{~L} / \mathrm{min})$ & $37(\mathrm{~L} / \mathrm{min})$ & $40(\mathrm{~L} / \mathrm{min})$ & $45(\mathrm{~L} / \mathrm{min})$ \\
\hline
\end{tabular}




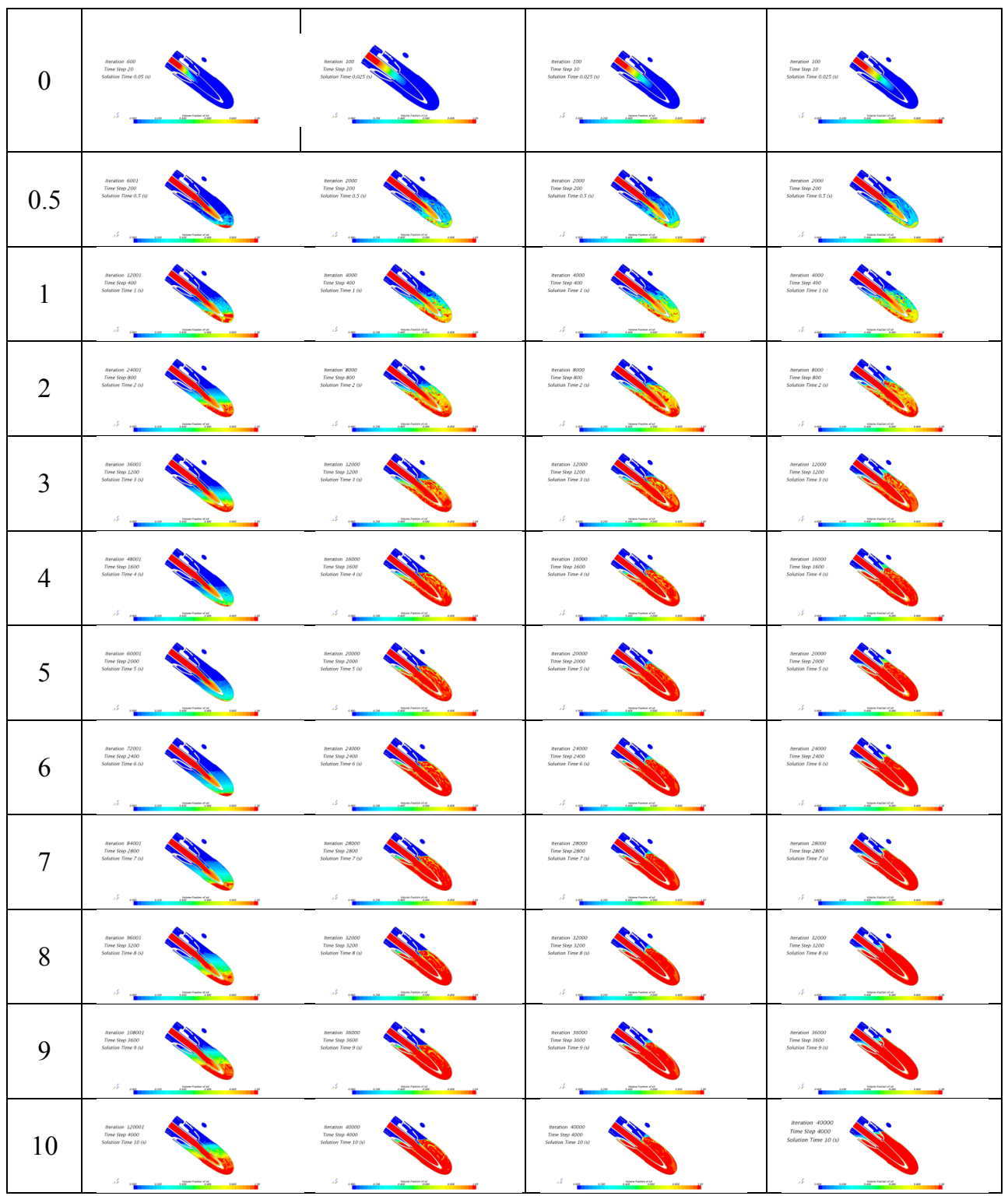

\subsection{Comparison of the bottom of the fuel pipe with different flow rates}

Table 4 shows the state of the dynamic fuel seal at the bottom of the fuel filler pipe under different fueling rate conditions. When the refueling rate is $15 \mathrm{~L} / \mathrm{min}$, the fuel flows to the bottom of the fuel pipe and flows into the fuel tank in the 2 second s. Before 5 seconds, the liquid seal is not formed, continue to refuel, and the bottom of the fuel pipe forms a stable fuel flow, Until 10 seconds, no dynamic liquid seal was formed.

When the refueling rate is $37 \mathrm{~L} / \mathrm{min}$, the fuel flows to the bottom of the fuel pipe and flows into the fuel tank in the 1 second $\mathrm{s}$. Before 5 seconds, the liquid seal is not formed, continue to refuel, and the bottom of the fuel pipe forms a stable fuel flow, Until 6 second at the bottom of the fuel filler pipe, a dynamic liquid seal is formed. 
When the refueling rate is $40 \mathrm{~L} / \mathrm{min}$, the fuel flows to the bottom of the fuel pipe and flows into the fuel tank in the 1 second s. Before 4 seconds, the liquid seal is not formed, continue to refuel, and the bottom of the fuel pipe forms a stable fuel flow, Until 5 second at the bottom of the fuel filler pipe, a dynamic liquid seal is formed.

When the refueling rate is $45 \mathrm{~L} / \mathrm{min}$, the fuel flows to the bottom of the fuel pipe and flows into the fuel tank in the 1 second s. Before 3 seconds, the liquid seal is not formed, continue to refuel, and the bottom of the fuel pipe forms a stable fuel flow, Until 4 second at the bottom of the fuel filler pipe, a dynamic liquid seal is formed.

From the above analysis, it can be concluded that the lower the refueling flow rate, the more difficult it is to form a dynamic liquid seal at the bottom of the fueling pipe. With the increase of the refueling flow rate, the dynamic liquid seal is more likely to form at the bottom of the fueling pipe, but the increase in the fueling flow rate generates fuel vapor. The rate is accelerated, and a higher air pressure is formed in the entire fuel filler pipe and the fuel tank, which is likely to cause the fuel in the fuel filler pipe to return to the swimming phenomenon, causing the fuel gun to jump ahead of time. Therefore, when designing the fuel system, it is necessary to consider the effect of refueling to produce a dynamic liquid seal. At the same time, it is necessary to consider that the pressure of the overall fuel system is controlled within a certain reasonable range, so as not to cause an increase in the refueling flow rate and cause the refueling gun to jump ahead of the gun..

Table 3. Comparison of the bottom of the fuel pipe with different flow rates.

\begin{tabular}{|c|c|c|c|c|}
\hline \multirow{2}{*}{$\begin{array}{c}\mathrm{Ti} \\
\mathrm{me}( \\
\mathrm{s})\end{array}$} & \multicolumn{4}{|c|}{ Refueling rate } \\
\hline & $15(\mathrm{~L} / \mathrm{min})$ & 37(L/min) & $40(\mathrm{~L} / \mathrm{min})$ & $45(\mathrm{~L} / \mathrm{min})$ \\
\hline 0 & & 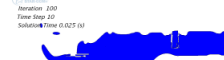 & 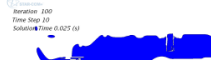 & 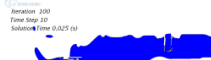 \\
\hline 0.5 & & & $=$ & 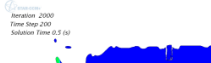 \\
\hline 1 & & & & 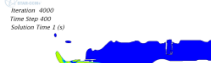 \\
\hline 2 & & & & \\
\hline 3 & 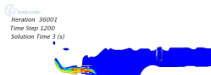 & & & \\
\hline 4 & & & & \\
\hline 5 & 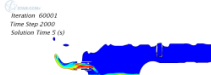 & $=$ & 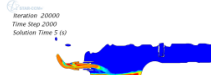 & 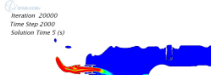 \\
\hline 6 & & $=$ & $=$ & $=$ \\
\hline 7 & $=$ & $=$ & $=$ & $=$ \\
\hline & $\ldots$ & $=$ & $=\ldots$ & 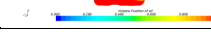 \\
\hline
\end{tabular}




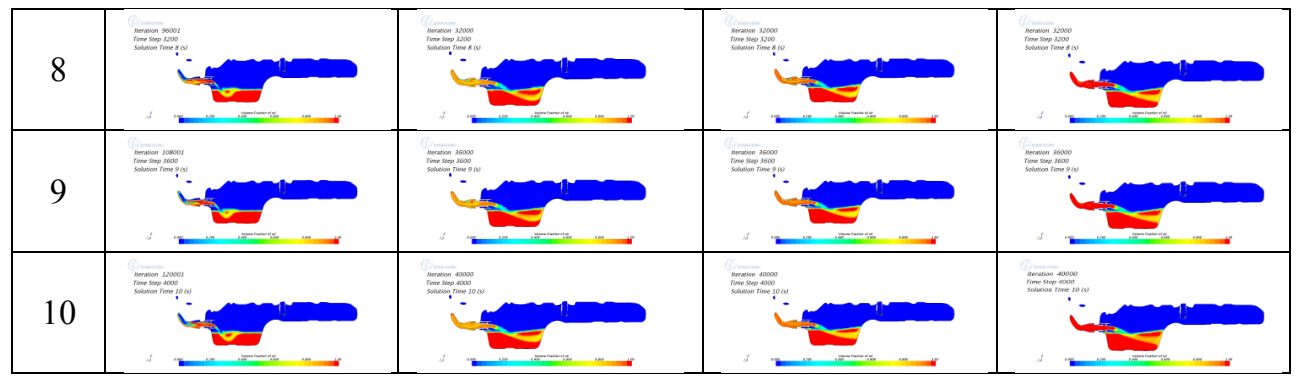

\section{Conclusions}

Based on STAR CCM + three-dimensional simulation software, a simulation model was established to study the smoothness of fueling in the fuel system, and the following conclusions were drawn:

1.The increase in the fuel flow rate promotes the formation of a liquid seal during the fuel flow of the fuel filler pipe, but it will result in poor fueling smoothness;

2.The lower the refueling flow rate, the more difficult it is to form a dynamic liquid seal at the bottom of the refueling pipe. With the increase of the refueling flow rate, the easier it is to form a dynamic liquid seal at the bottom of the refueling pipe. A higher air pressure is formed inside the fuel tank, which can easily cause the fuel in the fuel pipe to return to the swimming phenomenon, causing the fuel gun to jump ahead of time.

3. When the fuel flow rate is $15 \mathrm{~L} / \mathrm{min}$, no liquid seal is formed at the bottom of the fuel pipe; when the fuel flow rate reaches $37 \mathrm{~L} / \mathrm{min}$, a stable dynamic liquid seal can be formed at the bottom of the fuel pipe; when the fuel flow rate reaches $40 \mathrm{~L} / \mathrm{min}$ and $45 \mathrm{~L} / \mathrm{min}$ At the time, a stable dynamic liquid seal is quickly formed at the bottom of the fuel pipe, but there is more fuel accumulation at the head of the fuel pipe, and the poor smoothness of fueling may cause the gun to jump ahead of time.

On behalf of all the authors, the corresponding author states that there is no conflict of interest.

\section{References}

1. Yuan, B.; Hu, W. W.; Shao, M.; Wang, M. VOC Emissions, Evolutions and Contributions to SOA Formation at a Receptor Site in Eastern China. Atmos. Chem. Physics,13,17(2013-09-04) 2013, 13 (17), 8815 - 8832.

2. Huan Liu; Hanyang Man; Michael Tschantz, et al. VOC from Vehicular Evaporation Emissions: Status and Control Strategy [J] Science \& Technology, 49 (2015) 1442414431.

3. Yanli Zhang a,b, Xinming Wang a, *, Zhou Zhang,et al. Species profiles and normalized reactivity of volatile organic compounds from gasoline evaporation in China[J]. ELSEVIER, Atmospheric Environment 79 (2013) 110-118.

4. Kwangsam Na a, *, Yong Pyo Kim b, Il Moon a, et al. Chemical composition of major VOC emission sources in the Seoul atmosphere[J].ELSEVIER, Chemosphere 55 (2004) 585 - 594.

5. GB 18352.6-2016, Limits and measurement meth-ods for emissions from light-duty vehicles(China 6) [S]. 
6. CCR Title 13, CALIFORNIA EVAPORATIVE EMISSION STANDARDS AND TEST PROCEDURES FOR 2001 AND SUBSEQUENT MODEL MOTOR VEHICLES[S], 2015.

7. EPA 40CFR, FINAL RULE FOR AMENDMENTS RELATED TO TIER 3 MOTOR VEHICLE EMISSION AND FUEL STANDARDS[S], 2016.

8. EPA 40CFR Part86, Emissions from new \& In-use highway vehicle \& engines[S], 2016.

9. Yang X, Liu H, Cui H, et al. Vehicular volatile organic compounds losses due to refueling and diurnal process in China: 2010 - 2050[J]. Journal of Environmental Sciences, 2015, 33: 88-96.

10. Yue Xin,Pang Yuan, etl al. Enhancing Vehicle Fuel Evaporative Emission Control and Reducing Volatile Organic Compounds Pollution [J]. Environmental Protection,2014, 42(24):27-30.

11. Glenn W. Passavant Summary and Analysis of 2000-2015 Model Year IUVP Evaporative and Refueling Emission Data[R]. SAE Technical Paper 2017-01-5008, 2017, doi:10.4271/2017-01-5008.

12. A. Godbille and M. T. Bayliss A Parametric Vehicle Fuel Tank Filling System Model[R]. SAE Technical Paper, 2007-01-1741,2007.

13. Lockhart M C. Predicting tank vapor mass for on-board refueling vapor recovery[R]. SAE Technical Paper, 1997.

14. Mastroianni M. Experimental Investigation of Automotive Fuel Tank Filling, MA Sc[D]. Thesis, Mech., Auto. and Mat'ls Eng. Dept., University of Windsor, Windsor, ON, Canada, 2000.

15. Quigley C J. Refueling and evaporative emissions of volatile organic compounds from gasoline powered motor vehicles [D]. THE UNIVERSITY OF TEXAS AT AUSTIN, 2007.

16. Hiroyuki Yamada. Refueling emissions from cars in Japan: Compositions, temperature dependence and effect of vapor liquefied collection system [D]. Atmospheric Environment DOI:10.1016/j. atmosenv. 2015.09.026.

17. Dong Kyu Kim, Adsorption and desorption dynamics of evaporative fuel gas in canister of ORVR (On-Board Refueling Vapor Recovery) system[D]. Elsevier Science \& Technology, DOI:10.1016/S0167-2991(06)81693-9 2006 701-704.

18. Cai Jinrong. Designing and Modeling of Onboard Tefueling Vapor Recovery System \& Experiment Research.[D]. Su zhou: Jian Su University, 2010.

19. Zhang Yun. CFD Analysis on Evaporation during Refueling[D]. China: Jiang Shu University, 2018. 